\title{
A New Sociology for a New History? Further Critical Thoughts on the Eurasian Similarity and Great Divergence Theses ${ }^{1}$
}

JOSEPH M. BRYANT

In "The West and the Rest Revisited" (2006), I offered a critical assessment - theoretical as well as substantive - of recent revisionist scholarship that rejects standard explanatory accounts of the rise of the European powers to global dominance in the early modern period. ${ }^{2}$ While differing on select points of interpretation, revisionists are in broad agreement on two fundamental claims: $(a)$ the "advanced organic societies" across Eurasia were following comparable developmental paths, and $(b)$ the European breakthrough to hegemonic ascendancy was both late and fortuitous, decisively facilitated by energy and resource contingencies rather than endogenous developments. Neither postulate is compelling, either as sociology or as history. To subscribe to the revisionist narrative requires the unwarranted relegation of two securely established

1. I extend appreciation to Rod Nelson, Angus Maddison, Peer Vries, John Hall, Chris Isett, and Bernd Baldus for helpful commentary on draft versions of this essay; Michael Adas and Timur Kuran for guidance on a number of related interpretive challenges; and Paul Cartledge, Roger Beck, Brent Shaw, Ian Morris, and Daniel Tompkins for clarifications on the ancient economy debate. Members of the Center for Early Modern History at the University of Minnesota provided the gracious occasion for a trial run of some of the ideas presented here, and I hope they will discern a few signs that I benefitted from their instruction. Jack Goldstone generously shared his thoughts on the "Great Divergence" problematic in a number of preliminary communications leading up to this exchange, and I must register relief that he opted to save several of his more formidable arguments for his forthcoming book. A word of thanks as well to Kevin Haggerty, whose editorial responsiveness in all this has been exemplary.

2. The revisionist perspective is neither monolithic nor static; internal diversity and ongoing developments attest to a serious program of inquiry. A self-identified "school" does exist, however, to which even the more idiosyncratic members express allegiance. My criticisms range accordingly, from the general consensus to more particular arguments. 
analytical principles: that social formations are pervasively integrated and interdependent structures of institutional and cultural configuration; and that the historical processes variably reproducing and transforming those structures are not random or irregular, but unfold in path-dependent sequences that give rise to catenated trajectories of varying temporal duration. A viable historical social science is one that attends, connectively, to the dynamically coinciding "dual logics" of the sociological and the historical - a slighting of either, or both, will invariably skew or subvert the proffered analysis.

According to proponents of the "Eurasian Similarity thesis," the leading powers of the early modern period - Ming and Manchu China, Tokugawa Japan, Mughal India, the Ottomans and Safavids, and the western Europeans - were all functioning on the basis of fundamental comparabilities in productivity, living standards, commercial vitality, urban dynamism, and knowledge systems. But even on the intensely contested assumption that these novel empirical claims of equivalencies are plausible, the revisionist optic fatally marginalizes all the many institutional and cultural differences - in political structures, modes of war-making, legal-juridical arrangements, educational systems, kinship patterns, rural-urban interdependencies, class and status hierarchies, regnant worldviews, technological skill-levels, scientific comprehension of natural processes, etc. - that bore directly and indirectly upon the growing capacity of the European powers to establish coercive relations of dominance over much of the globe, beginning with limited ventures in mercantile brigandage at the end of the 15th century and continuing on to full-blown imperialism and colonization in centuries thereafter. As a comparative strategy for world history, a removal or displacement of the most centrally constitutive variables of social life not only injudiciously narrows and tilts our explanatory focus, it issues in highly misleading assimilations of societies that were keyed to profoundly differing institutional and cultural specifications.

Revisionists accomplish this conflation by shifting their focus to a level of abstraction that is higher-order, yet more restricted in content. In preference to the established multi-dimensional classifications (feudal, patrimonial, tributary, bureaucratic prebendalism, bourgeois-capitalist, proto-industrial, etc.), revisionists subsume all the major Eurasian powers under the arching rubric of "advanced organic societies," a one-dimensional categorization that indexes a common reliance on biomass resources and animal muscle-power that prevailed prior to any significant exploitation of fossil fuels. The energy factor, indisputably important, is thereby incautiously inflated to yield a new, coal-based binary of the 
"before" and "after" kind, which yields a reductive comparative sociology lacking in institutional and cultural concreteness. ${ }^{3}$

On the premise that purported East-West differences in social organization have been overdrawn, and that "surprising similarities" were holding across Eurasia up to $c .1800$, the revisionists are led to a corollary thesis. The European expansionary breakout is not to be traced to any long-term developmental dynamism, explicable in terms of successive institutional and cultural transformations, but to fortuitous accidents of geology and geography, which gave the Europeans abundant coal and proximity to the "windfall gains" they would extract from Africa and their New World colonies. As resource and energy constraints were thereby lifted, the Europeans would surge forward into capitalist industrialization and modernity, passing beyond their "advanced organic" peers in a late "Great Divergence" that ushered in a protracted period of Western domination. The new sociology that discounts or flattens variations in the institutional and the cultural is here met by a new kind of history that dispenses with the tracking of deep lines of cumulative causation and reconfigures the past in terms of long-persisting similarities, protracted lulls, and sudden discontinuities. On this view, macro-structural transformations occur abruptly, absent any extended preparatory or enabling developments. The inescapable implication is that a history of the shortterm or episodic is all that is required: the distally anterior imparts no momentum, no directionality; only the immediately preceding carries formative efficacy. Inheritances from antiquity, medieval transitions, the long pre-histories to, say, modern science, mechanized industrial production, the constitutional state, or the military revolution - all this lacks causal relevance in the making of the early modern world.

The vast scale and immense complexity of the phenomena under review - the rise of capitalism, colonial imperialism, the fashioning of modernist sensibilities and worldviews - leave one to wonder how an exclusionary bracketing of the socio-cultural or a foreshortening of temporal perspective can possibly herald an analytical advance? Both of my critics suggest I have misunderstood the revisionist argument, and underappreciate its empirical cogency. In reply, I will attempt to document that each continues to traffic in questionable sociologies and untenable histories.

3. E.A. Wrigley, who originated the idea for rather specific explanatory purposes, has recently offered an important critical take on revisionist misapplications of the "organic societies" concept, while also reaffirming significant economic growth in pre-modern England (2006). 


\section{The Goody School of World History Revisionism: Pars pRo toto Fallacies and Comparison by Elision}

A close student of the work of Jack Goody, Rosaire Langlois follows his mentor in reaffirming the Eurasian similarity and late Great Divergence theses. I confess to some difficulty in following the train of his argument, which flits across histories, geographies, and societies with an order or logic that escapes me. In confusing fashion, we are led breathlessly from one topic to another, ranging from Gorbachev's perestroika to Jefferson's meditative recourse to the exemplary Iroquois Confederacy (in his drafting of the American Constitution), and then all the way back to the Paleolithic, when the first hunting "democracies" were learning to tame their "alpha males." A great many signposts flash before us: Bruno's execution for heresy, the Catholic Index of prohibited books in 1565, "serf riots" and "wily kings," the expulsion of the Jews from England and Spain, More's Utopia and Montaigne's Noble Savage, the Taiping Rebellion, and even a cameo role for Stalin's Red Army, to which the West is said to be "beholden" for its democracy. The author is apparently of the view that these bare notices are sufficiently transparent to expose the evasions that burden mainstream scholarship. A number of studies based on "sound research" also find mention, though accompanying details are rare and sparse, leaving the reader to trust in the accuracy of Langlois's potted summaries. That, alas, would be a mistake, as shall be documented below.

From the drift and tenor of his commentary, there is no mistaking that Langlois holds imperialism and luck to be the master keys of history. He fires away, unfortunately, under the curious view that prior to the arrival of his "heroic" revisionists, imperialism was a neglected or taboo subject in the social sciences. Before venturing so sweeping an indictment in print, a brief trip to a university library might have been in order; but was it beyond our accusant to simply type in "European colonialism" and "European imperialism" on a JSTOR search, which would have usefully directed him to some 50,000 combined entries? Had he consulted a representative sample of this scholarship, rather than presume its nonexistence, he might have offered something instructive on the issue; instead, we are presented with a demagogic appraisal of imperialism that is largely devoid of sociological content or historical specificity. ${ }^{4}$

4. For a corrective to Langlois's simplicities on this subject ("Europeans weren't just lucky, they were lucky many times over...", p. 141), the acclaimed multidimensional synthesis offered by Abernethy (2000) abounds in richly documented insights, with incisive takes on what he aptly styles "the explorecontrol-utilize syndrome" of European expansionism, and the devastatingly 
In Langlois's rendering, transoceanic conquests, empire-building, and colonization in the early modern period appear little more challenging than the fitting together of a few planks and sails and the recruitment of crews infested with pathogens of suitably virulent strain. The imperialism he berates, and causally credits as "the most economically vital and catalytic enabling factor in Europe's later dominance" (2008: 134) simply arrives - much like Goody's Industrial Revolution - without any grounding in prior scientific or technological advances, political and economic transformations, or upgrades in military capacity. ${ }^{5}$ Fulminating against my argument that "luck" is neither a strong nor an autonomous explanatory principle, Langlois derides any suggestion that the European surge to coercive dominance was made possible by any developmental dynamism prior to 1492 , or that advanced sciences and technologies were decisive in the process. Much like his mentor, Langlois is zealous in linking - and thus confusing - attempted factual explanations of shifting power differentials in world history with a normative Eurocentrism, a triumphalist boasting of purportedly "unique" European accomplishments masquerading as comparative analysis. How else to read his caricatured summary of my position? "Crudely put," he incredulously intones, "European ingenuity" (p. 140).

Though I have never invoked "ingenuity" as an explanatory category, and would favor tracing this panhuman capacity to whatever social conditions might facilitate and channel its uneven expression, the connotations of the term are perhaps more relevant to our historical problematic than the dismissals by Goody and Langlois would have us believe. Consider these observations by Cheng Tingzuo (1691-1767), a noted sage from the Manchu era:

Far-off Europe!... Its people are known for their many-sided cleverness, excelling particularly at mathematics. Apart from this, everything else is excessive ingenuity, enough to amaze those of little knowledge. Often to play around with things is to bring myriad burdens on oneself. They have investigated to the utmost such cruel things as firearms (translated by and quoted in Elvin, 1996: 97; my italics).

effective "triple assault" it directed against indigenous polities, economies, and worldviews.

5. Goody's flattening of Eurasian cultural and institutional histories from the Bronze Age onwards leaves him in a quandary when it comes to explicating the eventual European breakthrough. The difficulty manifests even in his syntax, as with this involuted assertion that the Industrial Revolution "had its roots elsewhere but which later did introduce a temporary European advantage, based not on a previous superiority but on an existing comparability" (2004:159). A "roots elsewhere, existing comparability" argument for the emergence of any major structural transformation is logically incoherent. 
The pertinent phrase, yin qiao, "excessive ingenuity," a lexical compound dating back to the Confucian classics, appears to have figured prominently in the vocabulary of description used by scholar-officials for characterizing their unnerving European visitors. ${ }^{6}$ While one could dismiss all this, patronizingly, as simply yet another instance of innocent locals being duped by imperialist bluff and propaganda, would such an interpretation justify neglecting the implications of ideology entirely? Unfortunately, neither Goody nor Langlois think much of Weber's Verstehende Soziologie, or its methodological injunction that our explanatory efforts be disciplined by attentiveness to the subjective experiences and representations of the actors we are attempting to comprehend. A historical sociology unburdened by the responsibility of securing a modicum of hermeneutical adequacy for other times and different cultures is likely to commit more than the occasional projective anachronism, selectively recasting the past along lines serviceable to presentist agendas, scholarly or otherwise.

When we turn to Langlois's substantive presentation of the revisionist case, largely by way of staccato quotes and summaries from a range of authorities, we encounter a dilemma: is the testimony reliably reported? He is not above misrepresenting my own positions, as two examples will illustrate.

He alleges I credit the West with a distinctive rationalism that "fostered a culture of "continuous invention" (p. 413) since Greek and Roman times, distinguishing Europe from the Rest" (Langlois, 2008:136). Readers who examine page 413 will see I make no such claim, and that it is Langlois who deceptively supplies the historically absurd specification "since Greek and Roman times," as if a protracted Dark Age period of ruinous material contraction did not follow the Roman collapse (see now, importantly, Ward-Perkins, 2005, and Wickham, 2005). Moreover, the section offers a critique of Goody's peculiar insistence that "inventiveness" abounds in all times and places, against which I proposed that

6. I owe these philological details to Mark Elvin, who in private communication generously commented on these and related materials. See also his translation of Xue Shiyu's poem on the Western paddle-steamer, the opening lines of which merit mention here: "When the sages fashioned vessels of old, they forbade excess ingenuity. The dimensions of their boats and carts were everywhere the same. The exploitation of hill and marsh was not an unrestrained pursuit.... In handling fire they did not give to it lordship over the water. How could they have ever thought to put such wheels upon a warship? Their intelligence and intuition were in no way inferior, but they would not pit their human skill against the gods' achievements" (1996:98). Considering our looming ecological crisis and the collective violence it will assuredly call forth, one might sensibly allow these venerable Confucians had a point. 
the prospects for "continuous inventiveness and effective application" are socially and historically variable.

In a parallel distortion, Langlois brands my discussion of democracy "deceptive and defective," and accuses me of "dismiss[ing] Goody's examples as 'transitional' (p. 414), leaving "not even a single case" (p. 415) outside of Europe" (p. 138). Here again he twists and repackages what I wrote. Noting that Goody provides only two references in support for his sweeping assertion that "there have been plenty of 'democratic' regimes in the East" (p. 414), I pointed out that neither of the scholars he cited suggests anything close to Goody's astonishing claim. Leo Oppenheim's classic work on ancient Mesopotamia places the palace-temple nexus and oligarchical interests at the centre of political power, while Romila Thapar's foundational study briefly mentions a "transitional" phase of "tribal republics" in regions peripheral to the major Indian kingdoms. As there is no attestation or documentation of "democracy" whatsoever, it is remarkable bravado that Langlois thinks Goody has supplied any concrete examples that could be evaluated. Moreover, he misquotes and distorts the "not even a single case" remark - concerning democratic polities outside of Europe - by attributing the negation to me, when the passage clearly places the onus probandi on Goody, namely, that his rhetorical declaration "comes to us without the requisite confirming details on even a single case in support" (2006:415, italics added). If, as Goody alleges and Langlois imagines, there have been "plenty of 'democratic' regimes in the East," why not take a few pages to enlighten us on the specifics of these remarkable discoveries?

Does Langlois's artifice stop at the misrepresentation of those he criticizes? Following up one of his cited studies, I discovered yet another troubling breach of accepted scholarly practice. Langlois states that "Acemoglu et al. conclude that the usual characteristics stressed by sociologists, specifically 'culture, religious Protestantism, war-making, Roman heritage, and features of the European state-system' (2004:549) are not the most important factors in explaining modernization" (2008:135, underline added). The article cited appeared in 2005, and the original passage actually reads "culture, religion, geography, and features of the European state system." Langlois, astonishingly, has substituted his own words in the quote, and dropped one from the original (as underlined). Whether this indicates a pattern of manipulation or a lapse in judgment is immaterial at this point; trust has been forfeited, and time is too scarce to waste on a wider audit. ${ }^{7}$ To set the record straight, however, let it be

7. Goody, alas, resorts to similar tactics. In his The Theft of History (2006), he deceptively misrepresents the position of the great classicist, Moses Finley, as articulated in his landmark study, The Ancient Economy. In delimiting his 
noted that the study in question affords scant comfort to the revisionist cause, as it quantifies rising Western economic growth vis-à-vis Asia prior to 1800 , and reaffirms the North-Thomas position on the importance of property rights and merchant involvement in representative politics. Acemoglu and his co-authors do downplay the relevance of war-making, the Reformation, and legacies from classical antiquity in explicating the rise of northwestern Europe, but these particular inferences rest on a series of questionable measurement and classification decisions that underpin their regression equations. To assess the impact of "Roman heritage," for example, might require more than a simple coding for past membership in its immense empire. Architecture, engineering, militarist traditions, republican principles, law - these, surely, are the bequests calling for appraisal.

Ultimately, the revisionist historiography of the Goody school must be judged in terms of the adequacy of its comparative method. The analytical flaws, I believe, are debilitating. The approach is not secured by systemic, in-depth comparisons, but features instead a profusion of decontextualized allusions or insinuations of alleged parallels, analogues,

topical focus, Finley carefully explains why he will not include for examination either the economic "prehistory" of Neolithic times or the "important, seminal civilizations of the ancient Near East," as these were distinct social formations, differing significantly from those of Greece and Rome (1973:2729). Here is Goody's repackaged version: "In this schema "history and prehistory should remain distinct subjects of inquiry.' That means excluding from consideration 'the important, seminal civilizations of the ancient Near East,' commonly thought of as prehistoric, whereas Greece was historic" (39). What Goody has done is to flagrantly fuse Finley's separate points about the Neolithic and the historic ancient Near East, conveying the false impression that Finley regarded ancient Mesopotamia, Egypt, Persia, etc., as "prehistoric," while elevating the Greeks to singular "historic" status. Goody's recourse to misrepresentation can be explained by the fact that his own fanciful Bronze Age similarity/continuity thesis is thoroughly undermined by Finley's clarifying observations: "What matters is the way in which the two civilizations (or complexes of cultures) diverge fundamentally at every point, in their social structures, in their power structures.... It is almost enough to point out that it is impossible to translate the word 'freedom,' eleutheria in Greek, libertas in Latin, ... into any ancient Near Eastern language.... The Near Eastern economies were dominated by large palace or temple-complexes, who owned the greater part of the arable, virtually monopolized anything that can be called 'industrial production' as well as foreign trade ... and organized the economic, military, political life of the society through a single complicated, bureaucratic, record-keeping operation.... None of this is relevant to the Graeco-Roman world until the conquests of Alexander the Great and later of the Romans incorporated large Near Eastern territories" (1973:28). Instead of confronting the substance of Finley's arguments, Goody plays ventriloquist and censures the Eurocentric views he himself has spuriously scripted. 
and equivalencies. We are told of ancient Indian and Mesopotamian "democracies" and "republics," of "bourgeois revolutions" throughout the Asian and Islamic worlds, of "parallel urban civilizations" across Eurasia, of comparable "knowledge systems" and levels of "technological inventiveness." But all this comes to us without much concern for (a) sociological specificity, (b) chronological placement, (c) questions of scale and function, or $(d)$ the contextual constitution of all these purported similarities. A succession of pars pro toto fallacies flows inexorably from this peculiar form of comparison, as nominal identifications of alleged similarities and equivalences in selected institutions, social practices, and cultural forms - disjointedly sundered from their locative settings - are used to underwrite macro-scalar claims to enduring Bronze Age legacies and fundamental Eurasian similarities at the societal and civilizational levels. But if phenomenon $\mathbf{X}$ has attributes $f, g, q, r, s$, and phenomenon $\mathbf{Y}$ has $f, g, t, u, v$, it will entail a massive compositional error to posit isomorphism or equivalence between $\mathbf{X}$ and $\mathbf{Y}$, simply on the partial matches $f$ and $g$. Yet this is what occurs repeatedly, whether the discussion concerns guns and libraries or laws and commerce. Islamic madrasas are the equivalents of early European universities; European urban communes with their ruling merchant oligarchies are sociologically similar to the imperially governed cities of the Eastern empires; ancient modes of factory production are much like those of the early industrial period, differing more in scale than in structure or organization. Do you still imagine that the agro-managerial autocracies of the Orient differ all that significantly from the so-called democratic or republican polities of Greece and Rome? Another Eurocentric illusion, seeing as a "tributary" regime is simply "a state which requires monetary support from its inhabitants and which therefore opens the way back to the "rule of the people' who provide that function" (Goody 2006:121). ${ }^{8}$

In following a comparative method that elides or thins out the specific variations and complex articulations that constitute actual institutional arrangements, acculturated practices, and framing worldviews, the Goody school leaves us with a set of leveling formalisms that fails to register or detect those differences in social organization and culture that issue in all the many shifts and turns in the multifaceted drama that is human history. Blurred distinctions, loose categorizations, and flaccid taxonomies are undoubtedly "more inclusive" in a peculiar sense, but it is not one commonly associated with the task or purpose of scientific investigation.

8. The historically consequential dissimilarities between European and Asian state structures and economies are insightfully explored in a major new contribution from Peer Vries (2008). 


\section{World History Revisionism, with a Twist: Goldstone's "Peculiar Path"}

The eminent historical sociologist Jack Goldstone has long been identified as a leading critic of orthodox narratives of the European rise to global ascendancy. He is hardly a representative revisionist, however, given his distinctive views on a number of important issues. His counter critique of my paper nonetheless reaffirms the core assumptions and claims of the revisionist paradigm, while also sketching out the lead principles of his revised revisionism. How sound is his hybrid offering?

Goldstone opens by rejecting what he calls "the standard story" of the Rise of the West. His key point, concisely stated, is that "whatever their institutional and cultural differences, there was in fact no significant divergence of material living standards in Europe from those in the advanced Asian societies until much later, $c .1800$ " (2008:119). I find this doubly problematic.

The idea that institutions and cultures have little or no bearing on material productivity or living standards conjures a radically implausible sociology. I doubt that even the most doctrinaire neo-classical economist would subscribe to such an extremist view, that material or economic practices simply unfold and operate according to an insular, autonomous logic. Agrarian relations, instruments of production, the organization of labour power, the social and technical logistics of commerce and trade, the appropriation and distribution of the surplus, the incentive structures - all of which bear directly on the capacities and purposes of production - are all thoroughly and variably constituted by the institutional patterns and worldviews that govern their local functionality. The revisionist need to "wall off" or downplay those determinant sociological differentia that underpin established East-West comparisons has here issued in an untenable analytical segregation of causal relations and processes that must be attended to in their reciprocal connections and interdependencies.

My second concern, correlated with this unwarranted suppression of socio-cultural variances, is that revisionists inexplicably raise "material living standards" (often of highly speculative econometric derivation) to some form of master index to gauge the comparative power and developmental possibilities of radically differing social formations - by which principle one might have expected Ptolemaic Egypt, and not Rome, to have assumed hegemonic primacy, or that Communist East Germany had a brighter future than Ireland or Spain.

Goldstone's particular twist on the revisionist argument proposes that the "only exception" to the Eurasian similarity thesis is Great Brit- 
ain, which "starting in the 18th century embarked on a peculiar path of unique industrial innovations that gave birth to a modern world" (p. 120). That singular historic breakthrough, he insists, was achieved largely on the basis of scientific advances - and the development of "engine science" most critically - that carried Britain beyond the energy constraints that had hitherto hemmed in all the other advanced organic societies. This position, uncannily similar to earlier affirmations of "English exceptionalism," marks a significant departure from the standard revisionist line, and it certainly comports with much of the established historical evidence. ${ }^{9}$

Far less persuasive, however, is Goldstone's insistence that "this peculiar British move to industrial innovation was not simply an outgrowth of broad European patterns of culture and institutions" (p. 120), but a "contingent outcome" of conditions that came together on only one side of the Channel. Is it not highly inconsistent and implausible, however, to propose "surprising similarities" across Eurasia, holding over many centuries, and yet view British accomplishments in science, technology, and industry as if these were entirely "home-grown" and uninfluenced by any contacts with their immediate neighbours, trading partners, and geo-political rivals? That Britain was in many ways the leader in modernizing developments does not imply that others - notably the Dutch, French, Italians, and Germans - contributed nothing essential to the mix, or were themselves not progressing along comparable paths, in science and technology, proto-industrialization, trade expansion, urbanization, political and military modernization, etc. Growing intra-European interdependence and exchange is abundantly documented from the late Middle Ages onwards, and particularly so in the domain of ideas, following the remarkable spread of universities and the mass production of texts made possible by Gutenberg's movable-type press (cf. Mandrou, 1978; Eisenstein, 1983). By restrictively planting all the seeds of modern

9. I remain skeptical, however, of Goldstone's effort here to present the rise of modern science as if this were largely an autonomous process, unrelated to preceding and concurrent modernizing trends in European societies ("it came out of intellectual developments in the means of empirical discovery through instrument-driven experimentation," leading on to a "sudden" application "to mining, manufacturing, transport, and military ends", pp. 130-31). Strictly "internalist" accounts in the history of science have generally been abandoned as part of a larger interpretive move away from idealist paradigms and narratives, and the reinforcing interplay between scientific insights and material uses assuredly predates Goldstone's markedly revisionist "after 1770 " temporal framing, as lengthy bibliographies on the subject of medieval science and technology readily attest (cf. Glick, Livesey, and Wallis, 2005). Indeed, even for the English case, Merton's classic study starts the sciencetechnology dynamic a good century and a half earlier (1970 [1938]). 
dynamism in English soil, and in allowing only the briefest of periods for their germination, Goldstone manages to remain aligned with a revisionist project that both underplays East-West differences and embraces contingencies and discontinuities at the expense of deeper temporalities and cumulative causation. But it is precisely these retained revisionist abridgments, I submit, that cut against the grain of sociological and historical realism. ${ }^{10}$

Goldstone claims there is strong empirical evidence for persisting Eurasian comparabilities in living standards, $c .1500$ to 1800 , such that the limits set by "organic" energy and resource constraints continued to hold, despite rising agricultural productivity, trade expansion, and proto-industrialization. Indeed, he argues that "in all of them, the material standard of living $c .1800$ was no greater than it had been $c .1500$; no effect of cultural or institutional dynamics leading to a materially superior civilization in the West is evident" (p. 121). This position forms the "empirical crux" of the dispute between revisionists and the established orthodoxies, and the matter is so multidimensional and burdened by data shortfalls that it is likely to resist easy settlement. That said, the evidence that has accumulated in support of the traditional view - over many decades of intensively detailed exploration - is both wide-ranging and abundant; incoming research, moreover, is now responding to, and pointedly rebutting, revisionist claims. The data in Goldstone's very own Table 1A, for example, on comparative living standards, is drawn from Broadberry and Gupta (2006), a study that explicitly rejects the thesis of a late Great Divergence. Not only do these two scholars affirm rising material standards in northwestern Europe for the period in question, they conclude that the "advanced parts of Asia in 1800 should be seen as on the same developmental level as the stagnating parts of the European periphery" (p. 2; additional data is provided in their 2007 study). Saito's (2005) comparative investigation shows that northwestern Europe significantly outpaced Tokugawa Japan in pre-modern economic growth,

10. Goldstone suggests that my opposition to strong contingency/discontinuity arguments betrays a commitment to "linear thinking" (p. 121). Not so, and it is a mistake to conflate path-dependent processes with either linear or teleological outcomes, given that path trajectories commonly feature surges, lulls, and turning points, and the directionality that obtains is sequential rather than grandly telic. My central point, rather, is "catenation" or "connectedness," wherein every past shapes or conditions its emergent present, and every exogenous contingency intersects with endogenous causal processes and existing structural arrangements. Goldstone's countering advocacy for a "quantum theory" of history (p. 121), with dramatic "jumps" and breaks in continuity, allows for socio-historical ruptures that strike me as ontological impossibilities. 
with rising GDP per capita attributable to capitalist transformations of the mercantile and agricultural sectors, which concurrently fostered widening income inequalities. Allen et al. (2005:16), on the basis of a rich data-set encompassing wages, prices, and consumption goods, conclude that even prior to the Industrial Revolution, "Asian living standards were at the low end of the European range." And, not least, in a series of synthesizing studies incorporating the latest specialist research, Angus Maddison has charted and explicated economic development patterns on a world-historical scale, consistently documenting a widening gap between western Europe and the major Asian economies, c.1300 to 1820, in estimated GDP per capita and in related indicators of modernizing growth $(2003,2005,2006){ }^{11}$

Moreover, as Maddison and others have noted, there are serious problems of reliability and representativeness with the "purchasing power parity" or "real wage" estimates that revisionists privilege in discounting any significant rise in European living standards prior to the Industrial Revolution. Apart from being based largely on narrow or specialized employment sectors (the building trades, usually, or unskilled agricultural labourers), and on spotty temporal and regional records, there is also uncertainty over the likely number of working days per annum and, with rural handicrafts, the extent of domestic self-provisioning in textile and food staples. Ventures in econometric calculation here are thus tenuously underwritten by parametric assumptions that are both inference-sensitive and markedly variable. More fundamentally, "real wages" cannot serve as a proxy for either general living standards or levels of national or aggregate wealth. The important study by Hoffman et al. (2002) is particularly incisive on this issue, carefully documenting how price-shifts in basic consumption staples relative to luxury items and services, over the period 1500 to 1815 , issued in significant gains in prosperity and discretionary spending for European elites and the rising middles classes. A focus on "real wages" can thus mask the more important questions concerning the changing scale of the overall surplus (trends in GDP per capita) and its differential appropriation (inequality levels). Indeed, in

11. The surprising claims by Goldstone and Pomeranz that late Imperial China experienced an "agricultural revolution no less profound than that of Britain" (p. 131), as abetted by increased use of fertilizers and double-cropping, has recently been subject to a forceful critique by Yong Xue (2007). Xue not only establishes that the likely quantity of beancake fertilizer imported to the Yangzi delta region was only about 10 percent of the massive overestimation proposed by revisionists, he also finds abundant evidence confirming the traditional picture of a deepening involutionary crisis, due largely to soil exhaustion and declining marginal returns on labour. For the wider political economy, see Isett (2006). 
an emerging capitalist order, it is highly unlikely that the income share of the working population would track the dynamism and growth of the economy as a whole, rather than the shifting balance of class forces and the new means of surplus extraction. By failing to factor in what might be called the exploitation quotient, revisionist "real wage" estimates of comparative living standards misleadingly screen or occlude the operative systems of institutionalized inequality - i.e., the prevailing array of taxation policies, corvée, market mechanisms, occupational structures, legal status distinctions, etc. - that differentially (and decisively) shape the life chances of the proprietary and labouring strata.

All econometric studies of "pre-statistical" societies are forced to negotiate daunting and often impossible data and interpretation problems. The burden of persuasion for revisionists is greater still, seeing as their insistence on Asian equivalencies in material production as late as 1800 renders it difficult to comprehend the West's coercive advance over the prior three centuries. Goldstone attempts to deal with this by contesting the standard narrative of Western imperialism in Asia. I think his version misleads.

In presenting a "test of strength" interpretation that infers relative potency largely in terms of chronology - i.e., when did European control become preponderant? - Goldstone is assuming that $(a)$ the Portuguese, Dutch, English, and French all set sail for Eastern waters with colonizing, rather than commercial, intent, and $(b)$ a dilatory establishment of territorial control, or its absence, reflects both the continuing prowess of the Asian states and comparative weakness of the Europeans. This is to read history backwards, for it is clear that the European presence was overwhelmingly mercantile in its opening phases, and that more coercive arrangements - protection rents, coastal enclaves, trade monopolies, regional protectorates, tribute and taxation, commercial plantations sustained by forced labour, land expropriations - were imposed as opportunities manifested, rather than as a premeditated, relentless drive to conquest from Vasco da Gama onwards. Goldstone's declaration that "China and Japan, even Persia and Thailand, were able to repulse the Europeans and avoid colonization altogether" (p. 127) conveys a false impression that vast European fleets and armies were challenging Asian forces in a continuous struggle for Lebensraum and mastery, when in fact their early military presence was astonishingly small, and only subsequently rose to substantial scale through the recruitment of indigenous troops and local allies. The sequence-order of European imperial consolidations was thus largely determined by the immense logistical challenges of conducting transoceanic operations, limited manpower resources, the shareholder's 
demand for profitability, and not least, costly and incessant inter-European rivalry for hegemony. ${ }^{12}$

Goldstone's rhetorical analogy with the Vandals and Mongols fails to register the fact that the European advance was made possible by a range of vastly superior power capacities based on rapidly improving technologies. Indeed, in cases where Asian powers did temporarily reclaim lost positions or stage prolonged resistance, they commonly did so through the partial adoption of western weaponry, tactics, and organization (see Ralston, 1990). Goldstone refers to the famed rebel-pirate Coxinga, "who controlled the south China seas, not Europeans" (p. 127), but fails to mention that the war junks he deployed had been upgraded along western lines and carried European cannons, courtesy of previous alliances and trade with the Dutch (Andrade 2005). When the Manchus were threatened by the "Three Feudatories" rebellion (1673-81), they turned to a Jesuit, Ferdinand Verbiest, who directed the casting of mobile artillery pieces of his own design (Di Cosmo 2001). Indeed, as European military superiority was difficult for contemporaries to miss, it became commonplace for vulnerable dynasts or aspiring potentates to seek the services and skills of European advisors, commanders, gunners, engineers, and technicians, whose contributions were often crucial in deciding local power struggles (Scammell 1992). ${ }^{13}$

12.Far from "repulsing" the Europeans, Siam/Thailand was forced to cede significant eastern and southern territories to France and Britain respectively, and its success in preserving autonomy was due largely to the "westernizing" modernization ushered in by its reformist monarchy, and diplomatic skill in pitting European rivals against each other. As for Persia, it lost provinces and control over the Caspian to the modernized forces of Peter the Great in the 1722-23 conflict, and suffered additional territorial losses in the RussoPersian wars of 1804-13 and 1826-28.

13. As Chase establishes in his insightful geo-political comparative study, Europeans assumed a military superiority in training, tactics, logistics, and firearms from the early 1500 s, and this advantage widened rather than narrowed over time. Contrary to Goldstone's suggestion that the Chinese and Japanese enjoyed a military edge until the mid-1800s, Chase notes that "Chinese sources from the $1500 \mathrm{~s}$ and the $1600 \mathrm{~s}$ are full of comments on the superior quality of foreign firearms, and foreign observers likewise commented on the inferior quality of Chinese ones. It was clear to all that the Chinese were far behind" (2003:142). Similarly, all talk about formidable "coastal defenses" and "shore batteries" would appear to be belied by the fact that Ming and Manchu China experienced recurring difficulties in protecting coastal cities from piratical raids and assaults, with futility reaching such levels that the massive coastal population was forcibly evacuated inland, from 1662-69, for security purposes. The severe inadequacies of later Manchu coastal defenses are tellingly exposed in Antony (2006). 
In the arena of war, European knowledge of mathematics, chemistry, and physics - the science factor that Goldstone himself privileges - proved decisive, as it translated directly into pronounced martial superiority in metallurgy, ballistics, and explosives. Far from being latterday Vandals "bent on plunder" (p. 128), the European intruders were the carriers of new ideas, practices, and powers that would shatter established polities, economies, and cultures, and reorder much of the globe in long-enduring arrangements of exploitative hegemony and colonial domination. None of that bears much resemblance to the exploits of Attila, Gunderic, or even the great Genghiz.

\section{Conclusion: Refusals and Challenges in Comparative World History}

Revisionism is a necessary and ultimately constructive impulse in the ongoing pursuit of knowledge. Across the sciences and humanities, established positions and paradigms periodically encounter challenges - from the factual to the theoretical - that regularly issue in either progressive refinements of existing interpretations or, less commonly, in fundamental re-orderings of entire fields of inquiry. Yet the revisionist current carries an epistemic hazard as well, for there is a fine balance between constructive criticism, measured and precise, and that which, too sweepingly formulated, can foster paralyzing skepticism in the ability of scholars to deliver on the promise of genuine knowledge cumulation. The arbitration of revisionist claims, in other words, must be no less exacting than that which established orthodoxies repeatedly endure.

To dislodge or amend a prevailing perspective or explanatory paradigm, a revisionist alternative must yield some clear epistemological advantage over the orthodoxy it is challenging, typically in the form of a theoretical advance that justifies the proposed interpretive shift, or on the basis of new data sources that rectify or overturn earlier empirical characterizations. ${ }^{14}$ As presently constituted, the Goody and California schools of world history revisionism do not contribute much in the way

14. A revisionism lacking or deficient in progressive theoretical or substantive aspects is likely to register the intrusion of normative interests of socio-cultural derivation, as occasioned by shifts in the wider contexts within which intellectual pursuits are carried out. A proper sociology of knowledge for the revisionist case in hand cannot be attempted here, but there seems little doubt that the present phase of globalization - with its emerging reconfigurations of geo-political and economic hierarchies of dominance - has stimulated a quest for "usable pasts" that can supplant earlier grand narratives that now lack ideological resonance with current conditions. 
of either requirement. What the new polycentric paradigm represents, fundamentally, is an atheoretical shift in perspective, an inversional reclassification of phenomena already well-known and detailed, but reinterpreted in such a manner that what were formerly registered as differences and variations are now viewed as similarities and homologies. While laying claim to offering "a more inclusive story," revisionist world history is actually founded upon two analytical contractions: a sociological one that elides or marginalizes institutional and cultural specificities, and a temporal one that privileges the ephemeral and contingent over enduring legacies and gradational processes. Neither curtailment is justifiable, and each results in debilitating inconsistencies and aporias in the alternative narrative they propose: the bonded themes of protracted Eurasian similarities and a late Great Divergence. The explanatory conundra are logically inescapable. To the extent that revisionists diminish European power capabilities and advances (military, political, technological, scientific, economic), or "equalize" them relative to the major Asian empires, then the establishment of Western domination and exploitation becomes an inexplicable development - save for the sociologically evasive and vacuous invocation of bona fortuna. To the extent that revisionists discount the importance of long-term, path-dependent historical processes, and insist upon abrupt and radical discontinuities with the Industrial Revolution, they compress effective causality to the immediate short-term and reduce the immense complexities of macrostructural transformation to mere contingencies.

In stripping away or denying the determinant importance of social structural variances, and in sundering the distally anterior from the emerging present, revisionists of the Goody and California schools exclude from consideration far too many causally relevant relations and processes for the explanatory task at hand. We need neither a new sociology nor a new history; all that is required is a fully integrative and encompassing historical sociology.

\section{REFERENCES}

Abernethy, David. 2000. The Dynamics of Global Dominance. New Haven: Yale University Press.

Acemoglu, Daron, Simon Johnson, and James Robinson. 2005. The rise of Europe: Atlantic trade, institutional change, and economic growth. American Economic Review 95(3):546-79.

Allen, Robert, J-P. Bassino, Debin Ma, C. Moll-Murata, and Jan Luiten van Zanden. 2005. Wages, prices, and living standards in China, Japan, and Europe, 1738-1925. at www.iisgn.nl.hpw/factormarkets.php 
Andrade, Tonio. 2005. The company's Chinese pirates. Journal of World History 15(4):415-44.

Antony, Robert. 2006. State, community, and pirate suppression in Guangdong Province, 1809-1810. Late Imperial China 27(1):1-30.

Broadberry, Stephen and Bishnupriya Gupta. 2006. The early modern Great Divergence: Wages, prices and economic development in Europe and Asia, 1500-1800. Economic History Review 59(1):2-31.

2007. Monetary and real aspects of the Great Divergence between Europe and Asia, 1500-1800. Working Paper on the Global Economic History Network (GEHN), accessible at www.lse.ac.uk.

Bryant, Joseph M. 2006. The West and the rest revisited. Canadian Journal of Sociology 31(4):403-444.

Chase, Kenneth. 2003. Firearms: A Global History to 1700. Cambridge: Cambridge University Press.

Di Cosmo, Nicola. 2001. European technology and Manchu power. Pp. 119-39 in S. Sogner, ed., Making Sense of Global History. Oslo: Oslo University Press.

Eisenstein, Elizabeth. 1983. The Printing Revolution in Early Modern Europe. Cambridge: Cambridge University Press.

Elvin, Mark. 1996. Another History: Essays on China from a European Perspective. Canberra: Wild Peony.

Finley, Moses. 1973. The Ancient Economy. Berkeley: University of California Press.

Glick, Thomas, Steven Livesey, and Faith Wallis, eds. 2005. Medieval Science, Technology, and Medicine: An Encyclopedia. London: Routledge.

Goldstone, Jack. 2008. Capitalist origins, the advent of modernity, and coherent explanation: A response to Joseph M. Bryant. Canadian Journal of Sociology 33(1):119-133.

Goody, Jack. 2004. Capitalism and Modernity: The Great Debate. Cambridge: Polity Press.

2006. The Theft of History. Cambridge: Cambridge University Press.

Hoffman, Philip, David Jacks, Patricia Leven, and Peter Lindert. 2002. Real inequality in Europe since 1500. Journal of Economic History 62(2):32255.

Isett, Christopher. 2006. State, Peasant, and Merchant in Qing China, 16441862. Stanford: Stanford University Press.

Langlois, Rosaire. 2008. The closing of the sociological mind? Canadian Journal of Sociology 33(1):134-148.

Maddison, Angus. 2003. The World Economy: Historical Statistics. Paris: OECD. 2005. Measuring and Interpreting World Economic Performance, 15002001. Review of Income and Wealth 51(1):1-35. 
2006. Asia in the world economy, 1500-2030 AD. Asian Pacific Economic Literature 20(2):1-37.

Mandrou, Robert. 1978. From Humanism to Science, 1480-1700. New York: Pelican Books.

Merton, Robert K. 1970 [1938]. Science, Technology and Society in SeventeenthCentury England. New York: Harper \& Row.

Ralston, David. 1990. Importing the European Army. Chicago: University of Chicago Press.

Saito, Osamu. 2005. Pre-modern economic growth revisited: Japan and the West. Working Paper No. 16 on the Global Economic History Network (GEHN), accessible at www.lse.ac.uk.

Scammell, G.V. 1992. European exiles, renegades and outlaws in the maritime economy of Asia, c.1500-1750. Modern Asian Studies 26(4):641-61.

Vries, P.H.H. 2008. A World of Surprising Differences: State and Economy in Early Modern Western Europe and China. Leiden: Brill.

Ward-Perkins, Bryan. 2005. The Fall of Rome and the End of Civilization. Oxford: Oxford University Press.

Wickham, Chris. 2005. Framing the Early Middle Ages: Europe and the Mediterranean, 400-800. Oxford: Oxford University Press.

Wrigley, E.A. 2006. The transition to an advanced organic economy: Half a millennium of English agriculture. Economic History Review 59(3):43580 .

Xue, Yong. 2007. A 'fertilizer revolution': A critical response to Pomeranz's theory of geographic luck. Modern China 33(2):195-229.

Joseph M. Bryant holds a cross-appointment in the Sociology and Religion departments at the University of Toronto. He is the author of Moral Codes and Social Structure in Ancient Greece (1996) and recently coedited, with John Hall, a four-volume set entitled Historical Methods in the Social Sciences (2005). He is currently completing a book that combines his interests in the philosophy of science and the interpretive challenges posed by the rise of Christianity in the ancient Mediterranean world. Email contact: joseph.bryant@utoronto.ca 